\title{
Stratospheric ozone: History and concepts and interactions with climate
}

\author{
S. Bekki ${ }^{\mathrm{a}}$ and F. Lefevre
}

Laboratoire Atmosphères, Milieux, Observations Spatiales, Institut Pierre-Simon Laplace, Paris, France

\begin{abstract}
Résumé. Although in relatively low concentration of a few molecules per million of air molecules, atmospheric ozone (trioxygen $\mathrm{O}_{3}$ ) is essential to sustaining life on the surface of the Earth. Indeed, by absorbing solar radiation between 240 and $320 \mathrm{~nm}$, it shields living organisms including humans from the very harmful ultraviolet radiation UV-B. About $90 \%$ of the ozone resides in the stratosphere, a region that extends from the tropopause, whose altitude ranges from $7 \mathrm{~km}$ at the poles to $17 \mathrm{~km}$ in the tropics, to the stratopause located at about $50 \mathrm{~km}$ altitude. Stratospheric ozone is communally referred as the « ozone layer ». Unlike the atmosphere surrounding it, the stratosphere is vertically stratified and stable because the temperature increases with height within it. This particularity originates from heating produced by the absorption of UV radiation by stratospheric ozone. The present chapter describes the main mechanisms that govern the natural balance of ozone in the stratosphere, and its disruption under the influence of human activities.
\end{abstract}

\section{Introduction}

It is now well established that ozone is the most important species for the chemistry and radiative balance of the stratosphere. Its cycle is controlled by a range of chemical, dynamical and radiative processes. This chapter introduces the main concepts about the stratospheric ozone budget. We start by describing the main features of the global ozone distribution. Then, the basic chemistry of stratospheric ozone is reviewed. An analysis of the phenomenon of the so called « ozone hole $»$ is presented in the third section. The last section is devoted to the overall perturbation of stratospheric ozone by the emissions of ozone-destroying substances and the influence of climate change.

\section{Ozone distribution}

\subsection{Total column}

The efficiency of absorption of solar ultraviolet radiation (240 to $320 \mathrm{~nm}$ ) during its passage through the atmosphere depends on the thickness of the ozone layer, i.e. the total number of ozone molecules along the path of the sunrays. This thickness is called total column ozone, as it represents the total amount of ozone in a column of air extending from the surface to the top of the atmosphere. It is most often expressed in Dobson unit. Indeed, the first detailed measurements

a e-mail: slimane.bekki@latmos.ipsl.fr

Article published by EDP Sciences and available at http://www.epj-conferences.org or http://dx.doi.org/10.1140/epjconf/e2009-00914-y 


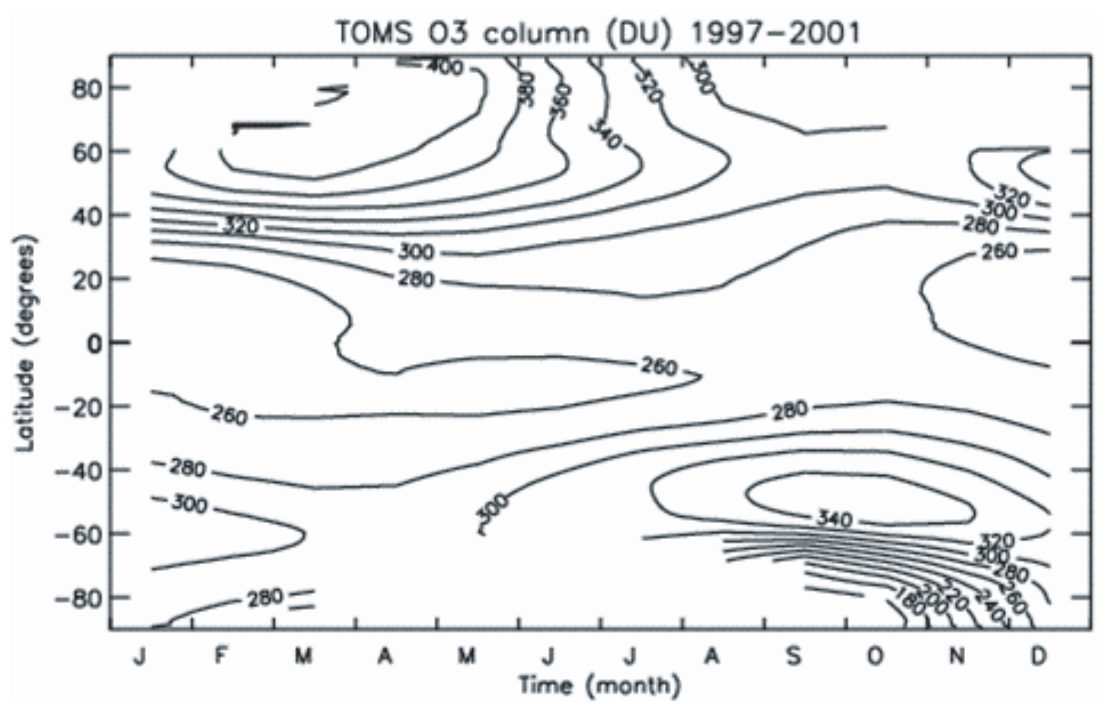

Fig. 1. Total column ozone (Dobson units, or DU) as a function of latitude and month. These values are derived from measurements of the instrument Satellite TOMS (Total Ozone Mapping Spectrometer) averaged for the years 1997 to 2001. The technique using ultraviolet radiation backscatter, data are absent in the regions of polar night.

of the ozone thickness were carried out by the meteorologist Gordon Dobson during the 1920s although the ozone layer was discovered by the physicists Charles Fabry and Henry Buisson in 1913. A Dobson unit corresponds to a theoretical thickness of one hundredth of a millimeter at standard temperature and pressure ( $273 \mathrm{~K}$ and 1 atmosphere) which represents $2.69 \times 10-16$ molecules of ozone per $\mathrm{cm}^{2}$. The annual average global total column ozone is of about $300 \mathrm{DU}$, which is equivalent to a $3 \mathrm{~mm}$ thick layer if all the ozone molecules were brought down to Earth's surface and uniformly distributed over the globe. The total ozone column varies seasonally and geographically as shown by Figure 1 .

Ozone is produced mainly in equatorial regions where solar radiation is sufficiently intense to dissociate continuously molecular oxygen. However, paradoxically, total column ozone is maximal near the poles, far from its production region (Fig. 1). In addition, the total column at high and middle latitudes is not correlated to the amount of available sunlight, since the ozone column tends to reach its peak during winter and spring instead of summer and its minimum in fall instead of winter. It is therefore clear that the spatio-temporal distribution of ozone in the stratosphere is not just determined by the photochemistry. The dynamical movement of air associated with the winds and the general circulation plays a fundamental role in transporting and redistributing ozone throughout the stratosphere. The relative importance of photochemistry and dynamics in the temporal and spatial variability of ozone depends on the considered altitude range in question. From $40 \mathrm{~km}$ to the stratopause, the ozone photochemical lifetime (which is defined as the " average » time a molecule exists before being destroyed by photochemical processes) is short, from a few hours to a day. In those conditions, transport processes can be neglected because they operate on much longer timescales in the stratosphere. Ozone is then in photochemical equilibrium and its concentration is determined by the ratio between its photochemical production and destruction. In contrast, in the lower stratosphere, between the tropopause and about $30 \mathrm{~km}$ altitude, the ozone photochemical lifetime is long, from a few days to several months. The variability of ozone is, in this case, controlled by the dynamical movements. As most of the ozone is found in the lower stratosphere, winds are thus able to carry large amounts of ozone far its production region (i.e. the tropics) towards middle and high latitudes, explaining the high ozone columns prevailing at high latitudes in winter. They can also cause 


\section{Colonne totale d'ozone}

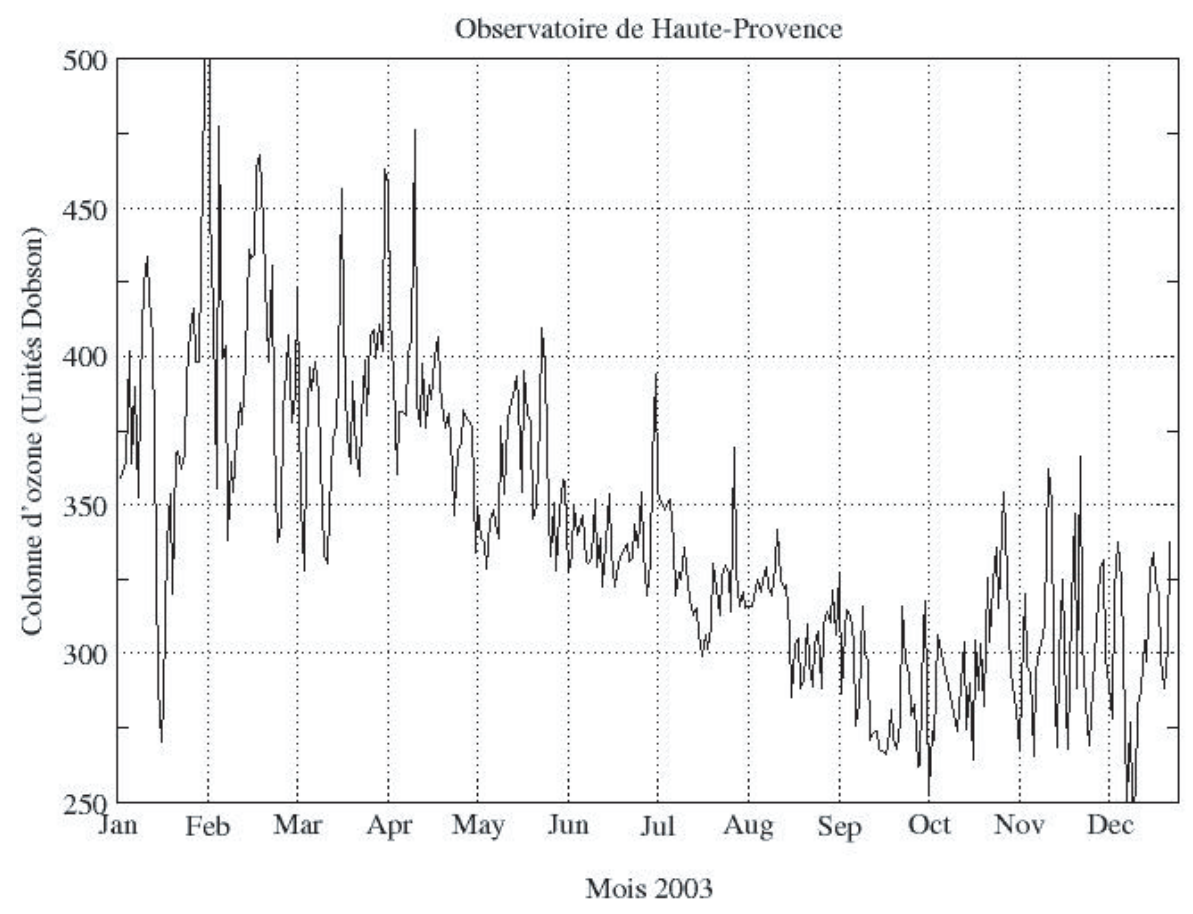

Fig. 2. Total ozone column (Dobson units) measured daily in 2003, by the SAOZ spectrometer based at the Haute Provence observatory.

large daily variations in ozone column, under the influence of meteorology. In the intermediate altitude range, the balance of ozone is more complex and results from the coupling between the photochemical and dynamic processes.

At large scale, the fact that the column ozone tends to be maximum at high latitudes and minimum in the tropics primarily results from the meridional transport. The latter is characterized in the lower stratosphere by an ascending motion in the tropics and subsidence at high latitudes during winter. The subsidence is associated with the existence of polar vortex, gigantic whirlwind of cyclonic circulation, created by the strong meridional gradient of temperature in the winter hemisphere. There are also differences between the hemispheres. In particular, the ozone column is maximum at the pole in the northern hemisphere, while the maximum is located in the $50-60{ }^{\circ} \mathrm{S}$ latitude band in the southern hemisphere. This asymmetry reflects the interhemispheric differences in the distribution and intensity of the winter subsidence. In general, it peaks at the edges of the polar vortex. In the southern hemisphere, the polar vortex is very cold and stable. Circular in shape, it remains centred above the pole and extends to about $65^{\circ}$ with ozone-rich air masses staying confined outside. In the Northern Hemisphere, the polar vortex is less cold and much less stable because of the greater activity of planetary waves which is linked to the complex distribution of continents at middle and high latitudes. The vortex tends often to drift towards the Northern Europe, which allows the ozone-rich air masses to reach the pole.

On the top of the seasonal variations in ozone column, large changes on much shorter timescales can be observed at and high latitudes. They can exceed $50 \%$ of the total content in a few days (Fig. 2). This variability is linked to dynamical systems of medium and synoptic scales, particularly active in winter, and to the associated transport of ozone. 


\section{Profils verticaux d'ozone}

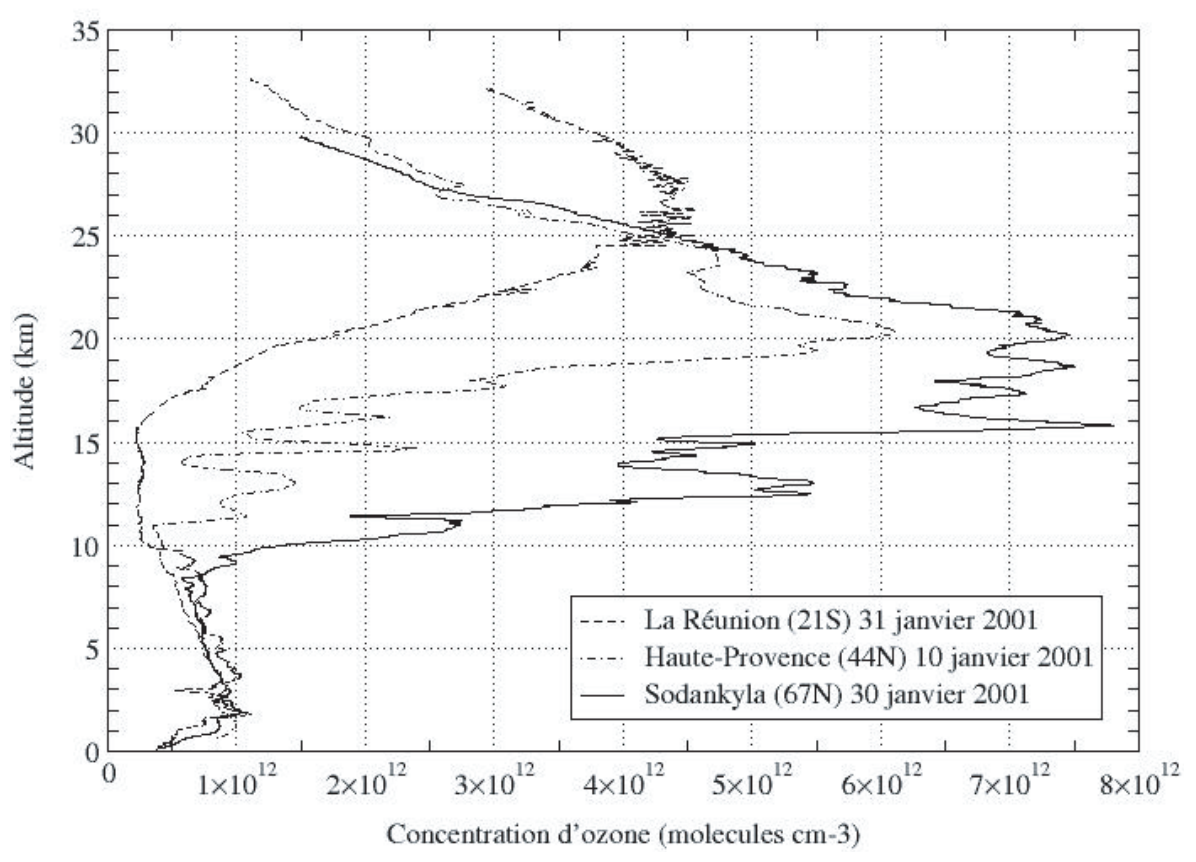

Fig. 3. Examples of vertical profiles of ozone concentration (molec. $\mathrm{cm}^{-3}$ measured in the tropics (Reunion, $21^{\circ} \mathrm{S}$ ), at middle latitudes (Haute-Provence, $44^{\circ} \mathrm{N}$ ), and polar regions (Sodankyla, $67^{\circ} \mathrm{N}$ ). The accumulation of ozone in the lower stratosphere winter is clearly visible. The laminated structures observed below $20 \mathrm{~km}$ result from the superposition of different air masses originated from different latitudes.

\subsection{Vertical distribution}

The ozone concentration is low in the troposphere, increases sharply from the tropopause to reach a maximum in the lower stratosphere, between 15 and $20 \mathrm{~km}$ at high latitude winter, and between 25 and $30 \mathrm{~km}$ in the tropics (Fig. 3). Above $30 \mathrm{~km}$, the ozone concentration decreases exponentially with height but less rapidly that the air density. This slower decline of the ozone concentration explains why the maximum ozone mixing ratio (= ozone concentration/air molecule concentration) is found above its maximum concentration. The mixing ratio reaches about $10 \mathrm{ppmv}$ (part par million per volume) at the equator at $35 \mathrm{~km}$ (Fig. 4). Unlike the major atmospheric constituents, such as nitrogen, molecular oxygen, carbon dioxide or methane, the ozone vertical profile does not exhibit a maximum at the Earth's surface and then a uniform decrease with height. Its particular vertical distribution results from the existence of a source of ozone in the stratosphere, and not at ground level.

As suggested by the latitudinal distribution of the ozone column, the analysis of the vertical distribution of stratospheric ozone concentrations reveals maximum concentrations at high latitudes in winter, and not in its production region in the tropics. This illustrates once again the importance of the mean meridional circulation in carrying ozone from the equatorial regions to the winter pole. This horizontal transport is accompanied by a slow movement of subsidence which is responsible for the decrease in the altitude of the ozone concentration maximum from the equator to the poles. 

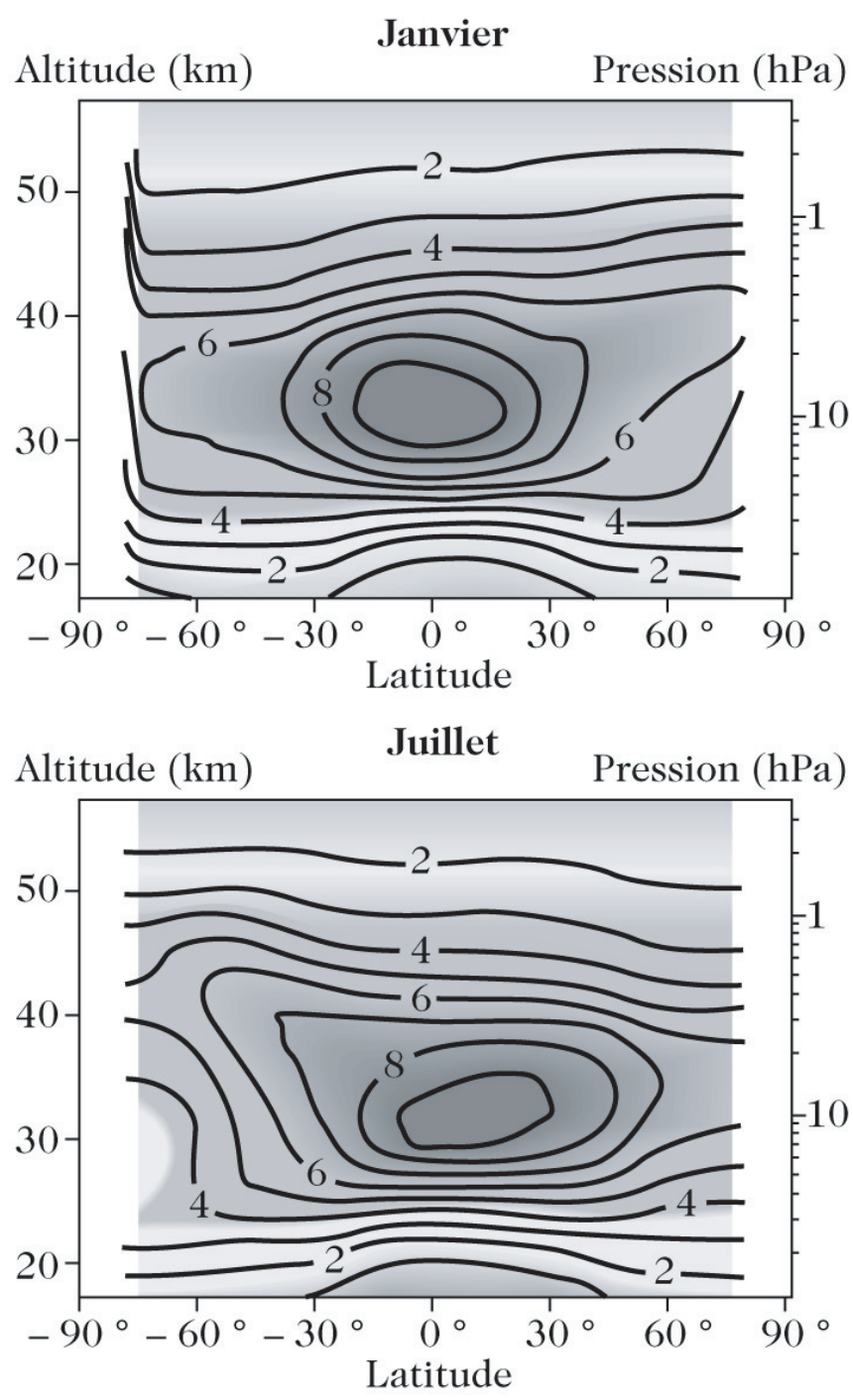

Fig. 4. Zonally averaged ozone mixing ratio (in ppm) as a function of latitude and altitude in January and July measured by the instruments HALOE and MLS on the satellite UARS (from [12]).

\section{Chemistry of global stratospheric ozone}

\subsection{Oxygen family}

Ozone is produced in the stratosphere by a mechanism involving the photolysis of molecular oxygen by solar ultraviolet radiation, followed by recombination between oxygen atoms formed and molecular oxygen.

\subsubsection{Photolysis of molecular oxygen}

The production of oxygen atoms by the photolysis of molecular oxygen is at the origin of the formation of the ozone layer in the stratosphere. It occurs only for wavelengths below $242 \mathrm{~nm}$ :

$$
\mathrm{O}_{2}+h \nu \stackrel{J_{\mathrm{O}_{2}}}{\longrightarrow} \mathrm{O}+\mathrm{O} \quad \lambda<242 \mathrm{~nm}
$$


where $\mathrm{J}_{\mathrm{O}_{2}}$ represents the rate of photolysis of molecular oxygen. The absorption spectrum of $\mathrm{O}_{2}$ can be broken down into several distinct areas whose importance in the photolysis varies with the altitude.

\subsubsection{Production of ozone}

Ozone is produced from oxygen atoms originating from the photolysis of molecular oxygen by the following three-body reaction:

$$
O+O_{2}+M \stackrel{k_{O+O_{2}}}{\longrightarrow} O_{3}+M(+\Delta Q)
$$

The third body $\mathrm{M}$ of this reaction is a molecule of nitrogen $\left(\mathrm{N}_{2}\right)$ or oxygen $\left(\mathrm{O}_{2}\right)$. This reaction is very fast and requires only a fraction of second in the stratosphere. It also causes a release of heat $\Delta \mathrm{Q}$ of $24 \mathrm{kcal}$ per mole of ozone formed, which corresponds to the energy of the liaison $\mathrm{O}-\mathrm{O}_{2}$ in the $\mathrm{O}_{3}$ molecule. This process explains the positive gradient temperature observed in the stratosphere.

\subsubsection{Photolysis of ozone}

Ozone has a low energy photolysis which, in theory, allows its dissociation for all wavelengths less than $1.14 \mathrm{~mm}$. The products, $\mathrm{O}$ and $\mathrm{O}_{2}$, are in a state energy that depends directly on the wavelength of the photon incident. However, transitions must obey to the rule of spin and, in practice, only two possible states for the oxygen atom produced are considered.

At wavelengths below about $310 \mathrm{~nm}$, the photolysis of ozone $\mathrm{J}_{\mathrm{O}_{3}}^{*}$ produces oxygen atom in the excited state $\mathrm{O}\left({ }^{1} \mathrm{D}\right)$ :

$$
O_{3}+h \nu \stackrel{J_{O_{3}}^{*}}{\longrightarrow} O_{2}+O\left({ }^{1} D\right) \quad \lambda<310 \mathrm{~nm} .
$$

The oxygen atom in its $\mathrm{O}\left({ }^{1} \mathrm{D}\right)$ state returns very quickly in its fundamental state $\mathrm{O}\left({ }^{3} \mathrm{P}\right)$ by collision with the main components of the atmosphere, $\mathrm{N}_{2}$ and $\mathrm{O}_{2}$ :

$$
\begin{aligned}
& O\left({ }^{1} D\right)+N_{2} \longrightarrow O\left({ }^{3} P\right)+N_{2} \\
& O\left({ }^{1} D\right)+O_{2} \longrightarrow O\left({ }^{3} P\right)+O_{2} .
\end{aligned}
$$

At wavelengths above $310 \mathrm{~nm}$, the photolysis of ozone $\mathrm{J}_{O_{3}}$ leads to the production of an oxygen atom in its ground state $\mathrm{O}(3 \mathrm{P})$ :

$$
\mathrm{O}_{3}+h \nu \stackrel{J_{O_{3}}}{\longrightarrow} O_{2}+O\left({ }^{3} P\right) \quad \lambda>310 \mathrm{~nm}
$$

\subsubsection{The Chapman cycle}

In 1930, the physicist Sydney Chapman proposed a theory that considers the balance between the formation and destruction of ozone from oxygen radicals only [1]. It lays the foundation of stratospheric ozone photochemistry. The sequence of selected reactions constitutes a cycle that allows developing a simple theory of stratospheric ozone in a pure oxygen atmosphere. The first step of this cycle involves the photolysis of molecular oxygen followed by the formation of ozone from the formed oxygen atoms (reaction R.1 and R.2). The atomic oxygen and ozone can be destroyed simultaneously by the reaction:

$$
\mathrm{O}+\mathrm{O}_{3} \stackrel{k_{\mathrm{O}+\mathrm{O}_{3}}}{\longrightarrow} \mathrm{O}_{2}+\mathrm{O}_{2}
$$


Finally, ozone is photolysed by:

$$
O_{3}+h \nu \stackrel{J_{O}^{\text {tot }}}{\longrightarrow} O_{2}+O
$$

where $\mathrm{J}_{O_{3}}^{\text {tot }}=\mathrm{J}_{\mathrm{O}_{3}}^{*}+\mathrm{J}_{\mathrm{O}_{3}}$. It is considered that the oxygen atoms excited $\mathrm{O}(1 \mathrm{D})$ produced by $\mathrm{J}_{O_{3}}$ is almost instantly deactivated back to its fundamental level $\mathrm{O}\left({ }^{3} \mathrm{P}\right)$, referred as $\mathrm{O}$ to simplify the notations. It is possible to establish the balance of ozone and atomic oxygen in the stratosphere from these reactions, considering only the oxygen species. Ignoring transport processes, the continuity equations describing the evolution of their concentration are expressed by:

$$
\begin{gathered}
\frac{d[O]}{d t}=2 J_{O_{2}}\left[O_{2}\right]+J_{O_{3}}^{t o t}\left[O_{3}\right]-k_{O+O_{2}}[O]\left[O_{2}\right][M]-k_{O+O_{3}}[O]\left[O_{3}\right] \\
\frac{d\left[O_{3}\right]}{d t}=k_{O+O_{2}}[O]\left[O_{2}\right][M]-J_{O_{3}}^{t o t}\left[O_{3}\right]-k_{O+O_{3}}[O]\left[O_{3}\right] .
\end{gathered}
$$

The disappearance of atomic oxygen is due to reactions R.2 and R.5. The reaction R.5 being several orders of magnitude slower than R.2, it can be neglected and thus define the photochemical lifetime of $\mathrm{O}$ atom by:

$$
\tau_{O} \simeq \frac{1}{k_{O+O_{2}}\left[O_{2}\right][M]} .
$$

At the top of the stratosphere where the pressure and thus $[\mathrm{M}]$ is low, $\tau_{O}$ is maximum but it only reaches a few tens of seconds. At lower altitudes, $[\mathrm{M}]$ increases rapidly and hence $\tau_{O}$ is even shorter. Because of its short lifetime, the oxygen atom $\mathrm{O}$ is always in photochemical equilibrium with ozone and molecular oxygen. The assumption of steady-state $\frac{d[O]}{d t}=0$ allows us to express the abundance ratio between $\mathrm{O}$ and $\mathrm{O}_{3}$, according to

$$
\frac{[O]}{\left[O_{3}\right]}=\frac{J_{O_{3}}^{t o t}+2 J_{O_{2}} \frac{\left[O_{2}\right]}{\left[O_{3}\right]}}{k_{O+O_{2}}\left[O_{2}\right][M]+k_{O+O_{3}}\left[O_{3}\right]} \simeq \frac{J_{O_{3}}^{t o t}}{k_{O+O_{2}}\left[O_{2}\right][M]} .
$$

The rate of ozone photolysis of $\mathrm{O}_{3}$ increases with altitude, while $[\mathrm{M}]$ decreases at the same time. The relative abundance of $\mathrm{O}$ compared to $\mathrm{O}_{3}$ increases rapidly with height. It is, however, only above about $60 \mathrm{~km}$ that the ratio $\frac{[O]}{\left[O_{3}\right]}$ becomes greater than 1 . Throughout the stratosphere, ozone concentration is greater than that of the oxygen atom by several orders of magnitude (Fig. 5).

It is important to note that the photolysis of ozone does not lead to a net loss of it. Indeed, the produced oxygen atom reacts immediately with $\mathrm{O}_{2}$ to reform ozone via reaction R.2. A rapid exchange between $\mathrm{O}_{3}$ and $\mathrm{O}$ operates throughout the stratosphere. In these circumstances, it is useful to define the family as Ox the sum of « odd oxygen »:

$$
\mathrm{O}_{x}=\mathrm{O}+\mathrm{O}_{3} .
$$

The evolution equation of Ox can be simply derived by adding the equations (1) and (2):

$$
\frac{d\left[O_{x}\right]}{d t}=2 J_{O_{2}}\left[O_{2}\right]-2 k_{O+O_{3}}[O]\left[O_{3}\right] .
$$

Note that the fast reactions R.2 and R.6 of exchange between $\mathrm{O}$ and $\mathrm{O}_{3}$ do not appear anymore in the evolution equation, which now contains a single term of production $\mathrm{J}_{\mathrm{O}_{2}}$, and a single term of loss, $k_{O+O_{3}}$. The photochemical lifetime of the Ox family may then be defined as:

$$
\tau_{O_{x}}=\frac{\left[O_{x}\right]}{2 k_{O+O_{3}}[O]\left[O_{3}\right]} .
$$




\section{1 mars $44 \mathrm{~N}$}

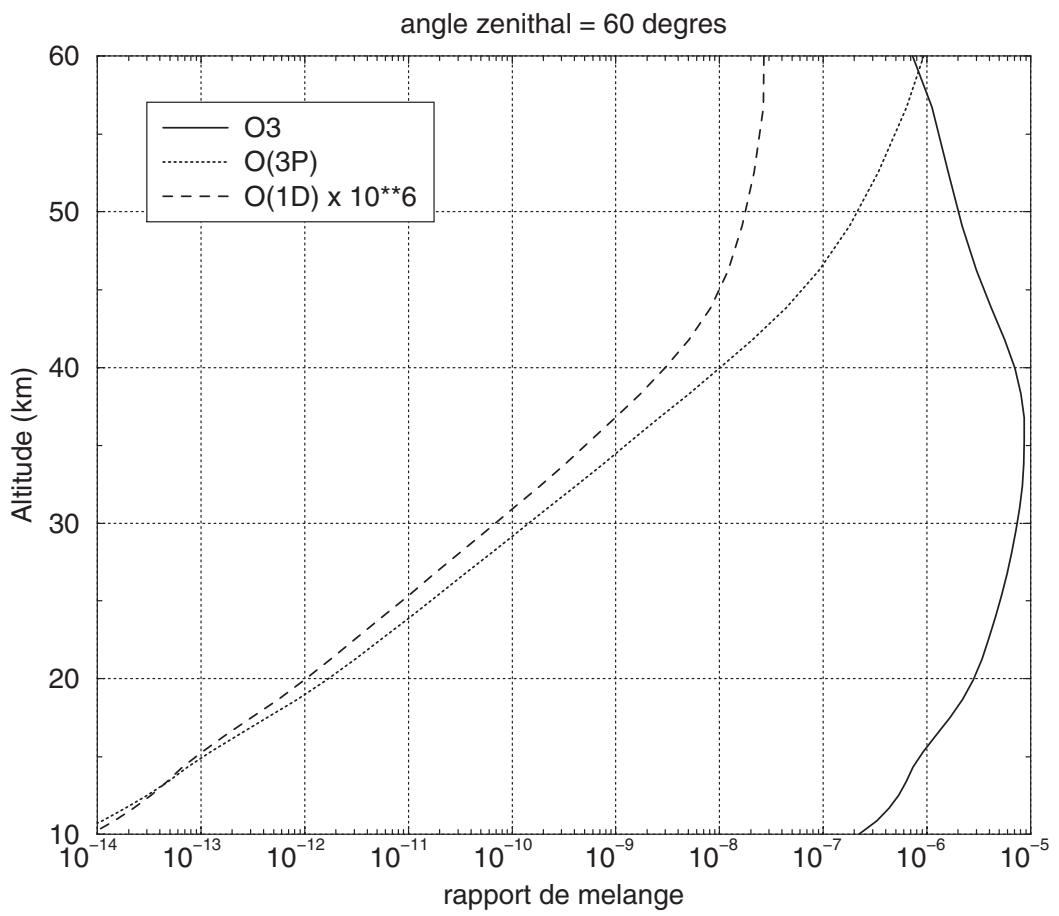

Fig. 5. Vertical profiles of day time $\mathrm{O}_{3}, \mathrm{O}\left({ }^{3} \mathrm{P}\right)$ and $\mathrm{O}\left({ }^{1} \mathrm{D}\right)$ volume mixing ratio calculated by the REPROBUS photochemical model at $44^{\circ} \mathrm{N}$ for spring equinox. For clarity, the mixing ratio of $\mathrm{O}(1 \mathrm{D})$ is here multiplied by a factor of $10^{6}$.

In the upper stratosphere, $\tau_{O_{x}}$ is about an hour and therefore the photochemical equilibrium can crudely assumed. The assumption of steady state $\frac{d\left[O_{x}\right]}{d t}=0$ allows to establish the equilibrium concentration of ozone by combining (2) with the ratio (3):

$$
\left[O_{3}\right] \simeq\left(\frac{k_{O+O_{2}}}{k_{O+O_{3}}} \frac{J_{O_{2}}}{J_{O_{3}}^{t o t}}[M]\left[O_{2}\right]^{2}\right)^{\frac{1}{2}} .
$$

In the middle and lower stratosphere, the lifetime of the family Ox increases rapidly when approaching the ground. Indeed, $\tau_{O_{x}}$ is about several days at $40 \mathrm{~km}$ but several weeks at $20 \mathrm{~km}$. The assumption of steady state is not valid anymore in the lower stratosphere, especially when photochemical lifetimes are compared to dynamical time constants. Ozone is also much more abundant than atomic oxygen. Combined with (3), the equation (4) becomes:

$$
\frac{d\left[O_{x}\right]}{d t}=\frac{d\left[O_{3}\right]}{d t}=2 J_{O_{2}}\left[O_{2}\right]-\frac{2 k_{O+O_{3}} J_{O_{3}}^{t o t}\left[O_{3}\right]^{2}}{k_{O+O_{2}}\left[O_{2}\right][M]} .
$$

The production rate of stratospheric ozone is therefore twice the photolysis rate of molecular oxygen. However, because of its photochemical life, there is no equivalence in the middle and lower stratosphere between regions of high ozone concentration and those of high production rate. The time constants associated with transport are in fact well below those associated with photochemistry, so that the horizontal and vertical distribution of ozone in the lower stratosphere is largely dictated by dynamics. 


\subsection{Ozone-destroying catalytic cycles}

The equation of odd oxygen evolution (4) shows the reaction R.5 as the only loss process in an atmosphere where only oxygen species are considered. However, this reaction is slow and, taking into account the ozone concentrations actually observed in the atmosphere, it cannot explain more than $20 \%$ of the destruction of Ox required to balance the production from molecular oxygen photolysis. In terms of vertical column, the calculation of it from only the Chapman cycle leads to a factor 2 overestimation of ozone column. Other chemical mechanisms of destruction of Ox must be considered. They involve minor constituents of the atmosphere, whose role in the chemical budget of ozone is based on the concept of chemical catalysis. In the case of ozone, the simplest catalytic cycles are of the form:

Cycle X

$$
\begin{aligned}
& \mathrm{X}+\mathrm{O}_{3} \longrightarrow \mathrm{XO}+\mathrm{O}_{2} \\
& \mathrm{XO}+\mathrm{O}^{k_{\mathrm{XO}+}} \stackrel{\mathrm{X}}{\longrightarrow}+\mathrm{O}_{2} \\
& \text { net: } \quad \mathrm{O}_{3}+\mathrm{O} \longrightarrow 2 \mathrm{O}_{2}
\end{aligned}
$$

where $\mathrm{X}$ is the minor constituent that is the catalyst of the cycle of reactions. The net overall reaction, reflecting the simultaneous disappearance of odd oxygen impairs, is equivalent to the reaction R.5. However, the reactions involved in the cycle above are much faster and are initiated by a catalyst, which, by definition, is not consumed in the process. One can then understand how a radical $\mathrm{X}$ with a concentration much lower than that of ozone (in practice, up to a million times less) can destroy a large number of species Ox, until it is converted into less reactive molecules, called « reservoirs ». The rate of destruction of $\mathrm{Ox}$ by the cycle $\mathrm{X}$ is determined by the rate of reaction $\mathrm{XO}+\mathrm{O}$. Indeed, it is much slower that the reaction $\mathrm{X}+\mathrm{O}_{3}$, which reform $\mathrm{XO}$ very quickly. The destruction rate of $\mathrm{Ox}$ by the cycle above can be written as:

$$
\frac{d\left[O_{x}\right]}{d t}=-2 k_{X O+O}[X O][O]
$$

where $\mathrm{k}_{X O+O}$ is the rate of the reaction between $\mathrm{XO}$ and $\mathrm{O}$. The factor 2 stems from the fact that two molecules of $\mathrm{Ox}$ are destroyed at each pass through the cycle. In the stratosphere, $\mathrm{X}$ corresponds to $\mathrm{H}, \mathrm{OH}, \mathrm{NO}, \mathrm{Cl}$ or $\mathrm{Br}$. The relative importance of these species depends on their concentrations and the reaction rates of their specific catalytic cycles. Whatever the catalyst $\mathrm{X}$ involved, it can be noted that the general cycle above requires the presence of atomic oxygen $\mathrm{O}$. Therefore, this type of process is effective only above $30 \mathrm{~km}$ altitude, when the concentration of O becomes sufficient. At lower altitudes, the destruction of odd oxygen occurs through other types of catalytic cycles, which do not require atomic oxygen.

\subsubsection{Hydrogen cycles}

The first catalytic cycles of ozone destruction have been identified in the early 1950s [2]. They involve hydrogen oxides radical $\mathrm{OH}$ and $\mathrm{HO}_{2}$. In the stratosphere, their production is mainly initiated by the photolysis of ozone producing atomic oxygen in its excited state $\mathrm{O}\left({ }^{1} \mathrm{D}\right) \cdot \mathrm{O}\left({ }^{1} \mathrm{D}\right)$ is a powerful oxidant, which reacts with a number of hydrogenated compounds to produce the hydroxyl radical $\mathrm{OH}$. The oxidation of water vapour by $\mathrm{O}(1 \mathrm{D})$ is the most important source of $\mathrm{OH}$ :

$$
\mathrm{O}\left({ }^{1} \mathrm{D}\right)+\mathrm{H}_{2} \mathrm{O} \longrightarrow \mathrm{OH}+\mathrm{OH}
$$


$\mathrm{OH}$ is also released by the oxidation of methane by $\mathrm{O}\left({ }^{1} \mathrm{D}\right) \cdot \mathrm{CH}_{4}$ is produced at the level of the soil but its long lifetime of about ten years allows it to reach the stratosphere. The third significant source of hydrogen radicals is the oxidation of molecular hydrogen by $\mathrm{O}\left({ }^{1} \mathrm{D}\right)$.

By replacing the catalyst $\mathrm{X}$ in the cycle described above by the hydroxyl radical $\mathrm{OH}$, a catalytic cycle is created. It is initiated by the very rapid reaction between the hydroxyl radical and ozone, which forms the hydroperoxyl radical $\mathrm{HO}_{2}$ :

Cycle 1

$$
\begin{array}{ll} 
& \mathrm{OH}+\mathrm{O}_{3} \longrightarrow \mathrm{HO}_{2}+\mathrm{O}_{2} \\
& \mathrm{HO}_{2}+\mathrm{O} \stackrel{\mathrm{k}_{\mathrm{HO}_{2}+\mathrm{O}}}{\longrightarrow} \mathrm{OH}+\mathrm{O}_{2} \\
\text { net: } \quad \mathrm{O}_{3}+\mathrm{O} \longrightarrow 2 \mathrm{O}_{2} .
\end{array}
$$

The slowest step in cycle 1 is the reaction between $\mathrm{HO}_{2}$ and $\mathrm{O}$. Once $\mathrm{OH}$ is formed, it reacts almost immediately with $\mathrm{O}_{3}$. The ozone destruction rate is given by $d\left[O_{3}\right] / d t=-2 k_{H_{2}}+O$ $\left[\mathrm{HO}_{2}\right][\mathrm{O}]$ (similar to the generic equation (3.1.4)). The efficiency of the cycle is limited by the available quantity of oxygen atoms $\mathrm{O}$. Cycle 1 plays an important role above $30 \mathrm{~km}$. At lower altitudes, the conversion of $\mathrm{HO}_{2}$ in $\mathrm{OH}$ can be achieved by direct reaction with ozone. The sequence of the two reactions $\mathrm{OH}$ and $\mathrm{HO}_{2}$ with $\mathrm{O}_{3}$ constitutes the following catalytic cycle that somewhat diverts from the canonical form $\mathrm{XO}+\mathrm{O}$ described above:

Cycle 2

$$
\begin{gathered}
\mathrm{OH}+\mathrm{O}_{3} \longrightarrow \mathrm{HO}_{2}+\mathrm{O}_{2} \\
\mathrm{HO}_{2}+\mathrm{O}_{3} \stackrel{{ }^{\mathrm{HO}_{2}+\mathrm{O}_{3}}}{\longrightarrow} \mathrm{OH}+\mathrm{O}_{2}+\mathrm{O}_{2} \\
\text { net: } \quad \mathrm{O}_{3}+\mathrm{O}_{3} \longrightarrow 3 \mathrm{O}_{2} .
\end{gathered}
$$

The kinetically limiting step in this cycle, also called rate-limiting step, is the reaction between $\mathrm{HO}_{2}$ and $\mathrm{O}_{3}$. As it does not use atomic oxygen, it is particularly important at low altitudes. It is indeed the primary mechanism of ozone destruction in the lower stratosphere at middle latitudes. There are other more minor ozone-destroying cycles involving hydrogen radicals.

In the same manner as $\mathrm{O}$ and $\mathrm{O}_{3}$, the reactions between $\mathrm{OH}$ and $\mathrm{HO}_{2}$ are very fast compared to those who produce or destroy these species. It is therefore useful to define the family $\mathrm{HOx}=$ $\mathrm{OH}+\mathrm{HO}_{2}$ (ignoring the $\mathrm{H}$ radical), and determine their relative abundances within the family from the assumption of photochemical equilibrium, which is justified for each of the hydrogen radicals. However, for an accurate calculation of the impact of $\mathrm{HOx}$ on ozone, their interaction with other atmospheric constituents cannot be neglected. For example, the reaction of $\mathrm{HO}_{2}$ with nitric oxide NO plays an important role in the lower stratosphere:

$$
\mathrm{HO}_{2}+\mathrm{NO} \longrightarrow \mathrm{OH}+\mathrm{NO}_{2}
$$

Unlike the reactions of $\mathrm{HO}_{2}$ with $\mathrm{O}$ and with $\mathrm{O}_{3}$, the reaction with $\mathrm{NO}$ converts back $\mathrm{HO}_{2}$ into $\mathrm{OH}$ without consuming odd oxygen. The presence of nitrogen oxides reduces the efficiency of HOx regarding ozone destruction. 


\subsubsection{Nitrogen cycle}

The importance of nitrogen oxides NOx in the balance of ozone on a global scale was pointed out in the early 1970s by Crutzen [3] and Johnston [4]. The main NOx source in the stratosphere comes from nitrous oxide $\mathrm{N}_{2} \mathrm{O}$ emitted at ground level by biological processes or linked to human activities. Its lifetime in the lower atmosphere is about 130 years, enabling it to reach the stratosphere, where it is either photolysed or destroyed by reaction with excited atomic oxygen $\mathrm{O}\left({ }^{1} \mathrm{D}\right)$. The only channel producing nitrogen radicals is the following reaction:

$$
\mathrm{N}_{2} \mathrm{O}+\mathrm{O}\left({ }^{1} \mathrm{D}\right) \longrightarrow \mathrm{NO}+\mathrm{NO}
$$

Note that this channel represents less than $5 \%$ of the total loss of $\mathrm{N}_{2} \mathrm{O}$ in the stratosphere. By replacing the catalyst $\mathrm{X}$ in the general cycle by the nitrogen oxide radical $\mathrm{NO}$, a catalytic cycle is formed:

Cycle 3

$$
\begin{array}{ll} 
& \mathrm{NO}+\mathrm{O}_{3} \longrightarrow \mathrm{NO}_{2}+\mathrm{O}_{2} \\
& \mathrm{NO}_{2}+\mathrm{O} \stackrel{\mathrm{kO}_{2}+\mathrm{O}}{\longrightarrow} \mathrm{NO}+\mathrm{O}_{2} \\
\text { net: } \quad \mathrm{O}_{3}+\mathrm{O} \longrightarrow 2 \mathrm{O}_{2} .
\end{array}
$$

The rate limiting step, is the $\mathrm{NO}_{2}+\mathrm{O}$ reaction because, once produced, $\mathrm{NO}$ reacts very quickly and almost entirely with $\mathrm{O}_{3}$ to reform $\mathrm{NO}_{2}$. The efficiency of the cycle is again determined by the abundance of oxygen atoms. It is therefore significant in the middle and high stratosphere.

The processes of exchange between $\mathrm{NO}$ and $\mathrm{NO}_{2}$ are fast and these compounds are usually grouped within the family of nitrogen oxides $\mathrm{NOx}=\mathrm{NO}+\mathrm{NO}_{2}$. Their abundance ratio $[\mathrm{NO}] /\left[\mathrm{NO}_{2}\right]$ within the family is easily derived by considering that $\mathrm{NO}_{2}$ is in photochemical equilibrium. This is the case during daytime because of the $\mathrm{NO}_{2}$ rapid photolysis. In the same way as for hydrogen radicals, nitrogen oxides interact with other chemical families, in particular hydrogen and chlorine families.

\subsubsection{Chlorine cycles}

The chlorine atom is present in many molecules of natural or industrial origin that are emitted at ground level. However, most of them are dissolved or destroyed at low altitudes before they can enter the stratosphere. The only significant natural source of stratospheric chlorine is the destruction of a chlorinated organic compound, methyl chloride $\mathrm{CH}_{3} \mathrm{Cl}$. Produced by the oceans, its lifetime is long enough (1 year) in the lower atmosphere for it to be transported in significant quantities into the stratosphere, where it is photolysed releasing chlorine atoms. On the top of this natural source, there have been industrial sources of chlorinated organic compounds, chlorofluorocarbons (CFCs), for over 50 years. Their lack of chemical reactivity results in very long lifetimes in the troposphere, of the order of several tens of years. Almost of all these compounds emitted at the surface enter the stratosphere, where their photolysis and oxidation release chlorine atoms. The chlorine produced is called inorganic chlorine, as opposed to chlorine trapped in chlorinated organic compounds. The main industrial sources of chlorine are $\mathrm{CFCl}_{3}(\mathrm{CFC}-11)$ and $\mathrm{CF}_{2} \mathrm{Cl}_{2}$ (CFC-12). These gases have a lifetime respective 45 and 100 years. The importance of the photolysis of CFCs as a source of chlorine radicals in the stratosphere, and the involvement of these species in the catalytic destruction of ozone have been mentioned first by Molina and 
Rowland in 1974 [5]. The chlorine atoms released react in effect very quickly with ozone and enter a catalytic cycle initiated by the reaction $\mathrm{X}+\mathrm{O}_{3}$, where $\mathrm{X}=\mathrm{Cl}$ :

Cycle 4

$$
\begin{aligned}
& \mathrm{Cl}+\mathrm{O}_{3} \longrightarrow \mathrm{ClO}+\mathrm{O}_{2} \\
& \mathrm{ClO}+\mathrm{O} \stackrel{k_{\mathrm{ClO}+\mathrm{O}}}{\longrightarrow} \mathrm{Cl}+\mathrm{O}_{2} \\
& \text { net: } \quad \mathrm{O}_{3}+\mathrm{O} \longrightarrow 2 \mathrm{O}_{2}
\end{aligned}
$$

$\mathrm{Cl}$ radical reacts rapidly and almost exclusively with $\mathrm{O}_{3}$ to reform $\mathrm{ClO}$. The efficiency of cycle 4 above is limited by the combination rate of $\mathrm{ClO}$ and $\mathrm{O}$ and therefore by the availability of oxygen atoms $\mathrm{O}$. Therefore, the destruction of odd oxygen by the catalytic cycle plays an important role in the upper stratosphere only. There are also other ozone-destroying cycles involving chlorine radicals. They involve couplings with radicals from different chemical family, in particular nitrogen oxides and hydrogen oxides.

\subsubsection{Bromine cycles}

Stratospheric bromine is produced from photolysis and oxidation by $\mathrm{OH}$ of brominated compounds emitted to the surface. The main one is methyl bromide $\mathrm{CH}_{3} \mathrm{Br}$. Its lifetime is slightly less than 1 year which allows a fraction of emissions to reach the lower stratosphere. $\mathrm{CH}_{3} \mathrm{Br}$ has natural and industrial sources. On the top of $\mathrm{CH}_{3} \mathrm{Br}$, there are brominated hydrocarbon compounds such as halons that are exclusively produced by industrial activities. The two most abundant are $\mathrm{CF}_{2} \mathrm{ClBr}(\mathrm{H}-1211)$ and $\mathrm{CF}_{3} \mathrm{Br}(\mathrm{H}-1301)$, whose lifetimes are 16 years and 65 years respectively. They are completely transported into the stratosphere where bromine atoms are released by the dissociation of the brominated organic compounds [6]. The total abundance of bromine species is of the order of $20 \mathrm{pptv}$ in the stratosphere. The most effective catalytic cycle involving bromine atoms is a cycle coupling bromine and chlorine radicals,

Cycle 5

$$
\begin{aligned}
& \mathrm{BrO}+\mathrm{ClO} \stackrel{\mathrm{BrO}_{\mathrm{BrO}} \mathrm{ClO}}{\longrightarrow} \mathrm{Br}+\mathrm{ClO}_{2} \\
& \mathrm{ClO}_{2}+\mathrm{M} \longrightarrow \mathrm{Cl}+\mathrm{O}_{2} \\
& \mathrm{Br}+\mathrm{O}_{3} \longrightarrow \mathrm{BrO}+\mathrm{O}_{2} \\
& \mathrm{Cl}+\mathrm{O}_{3} \longrightarrow \mathrm{ClO}+\mathrm{O}_{2} \\
& \text { net: } \quad 2 \mathrm{O}_{3} \longrightarrow 3 \mathrm{O}_{2} .
\end{aligned}
$$

The absence of effective reservoir species for bromine results in a partioning between reservoir and active species within the inorganic bromine family that is quite different from the partioning with the chlorine family. Thus, by day, about half of total stratospheric bromine is in the form of the ozone-destroying radical $\mathrm{BrO}$ (bromine monoxide), while $\mathrm{ClO}$ represents only less than one hundredth of the inorganic total chlorine. Consequently, the effectiveness of bromine atoms to destroy ozone is about 50 times higher than chlorine. But it should be kept in mind that the quantity of inorganic chlorine in the stratosphere is nearly 170 times that of inorganic bromine. 


\subsubsection{Reservoir species}

Although regenerated at the end of each cycle, catalysts of the Ox destruction do not have infinite lifetime in the stratosphere. After a certain period of activity, these radicals are sequestered temporarily in less reactive molecules, called « reservoirs » the more stable these reservoir species are, the more effective they are at storing (and so deactivating) radicals and so more effective they are at limiting the catalytic ozone destruction. In addition, most of the reservoir species tend to be soluble in water, which result in an irreversible loss when they are transported in the troposphere and eliminated by the rain. One can mention as examples of important reservoir species hydrogen peroxide $\mathrm{H}_{2} \mathrm{O}_{2}$ (hydrogen reservoir), nitric acid $\mathrm{HNO}_{3}$ (nitrogen and hydrogen reservoir) and chlorine nitrate $\mathrm{ClONO}_{2}$ (chlorine and nitrogen reservoir).

\section{Polar ozone}

The chemical processes described in the previous sections operate throughout the stratosphere. However, in addition to this global stratospheric chemistry, an unusual chemistry operates in the polar regions, during winter and spring. This is of utmost importance for the balance of polar ozone because it helps explain the sudden decrease of ozone concentration observed over the Antarctic since the early 1980s [7]. This phenomenon is known as the « ozone hole ». The same phenomenon is taking place above the Arctic in winter, although its intensity and scale are much more variable from one year to another.

\subsection{Observations}

\subsubsection{Ozone column}

The total column ozone has been regularly measured for several decades in the polar regions. In Antarctica, the observations until the late 1970s show an austral spring maximum, with an average over the month of October of about 350 Dobson Units (DU). This maximum results from a movement of large-scale subsidence during the winter that tends to accumulate ozone at high latitudes. From the early 1980s, a rapid and continuous decline in total column ozone is observed every spring above Antarctica. The average thickness of the ozone layer in October is currently close to 200 (Fig. 6). This is a monthly average. Daily data measured in late September or early October over Antarctica commonly show ozone column below 150 DU. Local minima below even $100 \mathrm{DU}$ are sometimes seen since the late 1990s, which represents the disappearance of nearly $70 \%$ of the total amount of ozone compared with measurements taken twenty years earlier. The satellite measurements have revealed the geographical extension of this phenomenon, known as the " ozone hole », with the reduction in ozone taking place over a wide circular area centred on the South pole. The surface area of the ozone hole has increased more or less continuously during the 1980s and 1990s and covers well beyond the entire Antarctic continent [8]. Although of large magnitude, it is important to note that the sudden decrease of ozone at high Southern latitudes remains a seasonal phenomenon. The ozone destruction indeed starts at the end of August, when sunlight is back on the edge of the polar vortex. The rate of ozone decrease peaks in September and minimum values for total column are usually reached between the last week of September to mid-October. They persist until the break-up of the polar vortex, which occurs around November. In general, the Antarctic ozone column quickly recovers values close to 1970s climatology at the end of December.

A decrease in ozone column of the same nature occurs in Northern polar regions. As at Southern high latitudes, the first signs of an ozone decline in the Arctic have emerged in the early 1980s. The maximum decrease is also observed in the spring, in March, and persists until the 


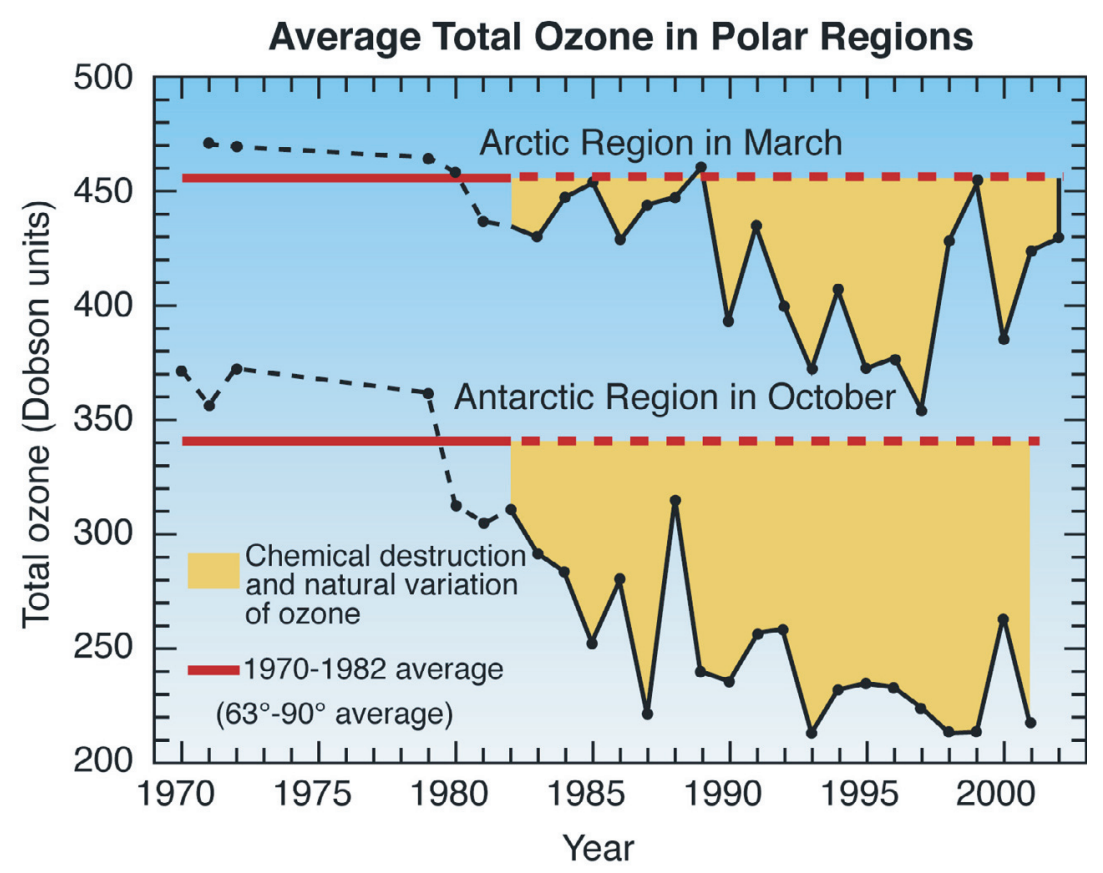

Fig. 6. Evolution of the monthly mean total polar ozone column measured by satellite (data are averaged over latitudes higher than $63^{\circ}$ ) for March in the northern hemisphere, and October in the southern hemisphere (from [8]).

break-up of the polar vortex. However, there are quantitative differences between the two polar regions. One of the most noticeable differences is the very strong Arctic interannual variability, which is linked to meteorological interannual variability. Compared to climatological values of the 1960s and 1970s, the ozone decrease in the Arctic spring can vary between something negligible in some years to a decline of nearly 100 DU during other years, as was the case in 1996 and 2000 for example [8]. This value is still much lower than the ozone reductions of at least 150 DU, commonly observed in Antarctica. Moreover, due to a meridional transport of ozone to the pole being more important in the Northern hemisphere than in the southern hemisphere, the polar ozone column in the early winter is higher in the Arctic than in the Antarctic. This differences in the initial conditions, combined with a decrease in total ozone generally less pronounced, explains why are an « ozone hole » of a magnitude comparable to the Antarctic one has not been observed over the Arctic.

\subsubsection{Ozone vertical profile}

Measurements of the ozone vertical profile above the polar regions show that the spring destruction occurs in an altitude range where the ozone concentration is usually maximum, i.e. in the lower stratosphere from approximately $15 \mathrm{~km}$ and $25 \mathrm{~km}$. In Antarctica, nearly $80 \%$ of the ozone disappears in this altitude range in October, when comparing to the average of profiles measured during the same month in the 1960s (Fig. 7). The analysis of individual profiles reveals a destruction even more pronounced with often a total disappearance of ozone over several $\mathrm{km}$ thick, as shown by the profile measured at the South Pole on 2 October 2001 (Fig. 7) with apparently a 
Antarctique

Pôle Sud $\left(90^{\circ} \mathrm{S}\right)$

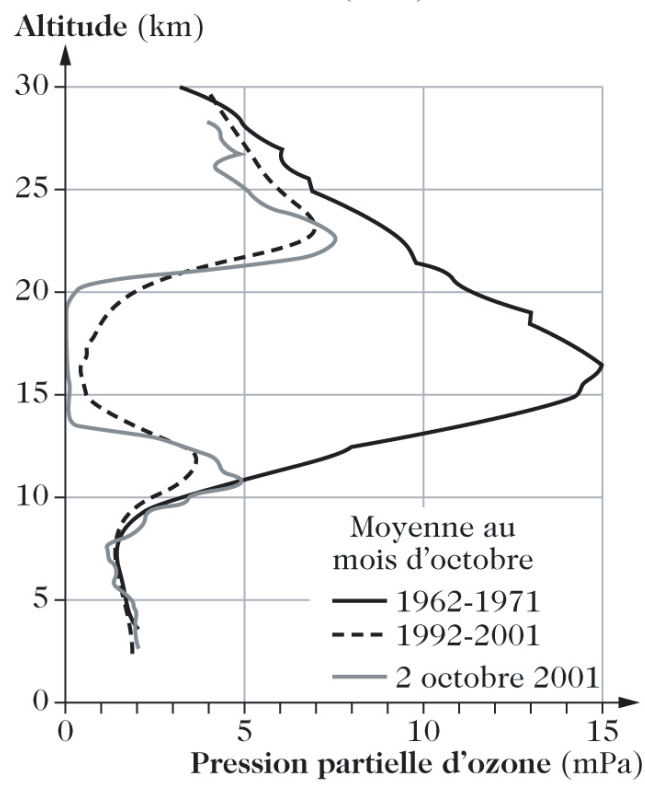

Aretique

Sodankylä, Finlande $\left(67^{\circ} \mathrm{N}\right)$

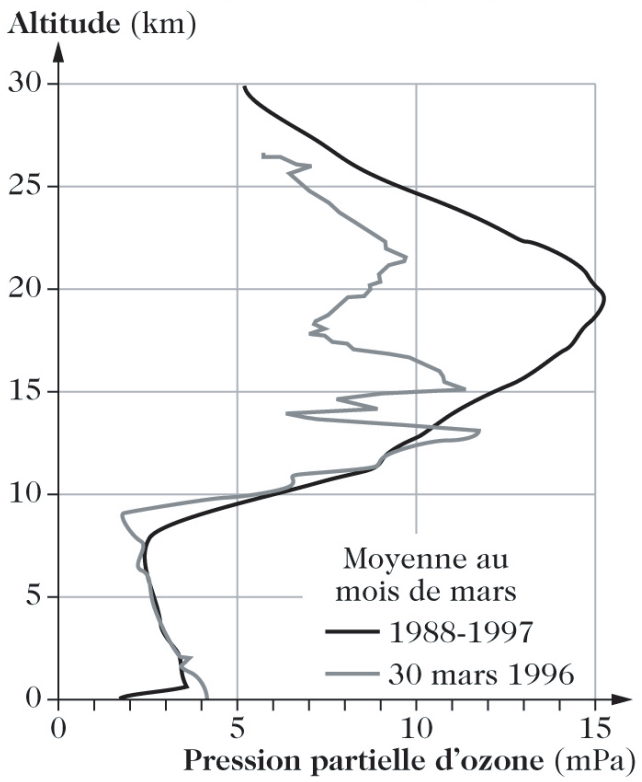

Fig. 7. Evolution of the vertical profile of ozone partial pressure, $(\mathrm{mPa})$ measured by ozone sonde in October above the South pole, and in March at the Arctic station of Sodankyla, $67^{\circ} \mathrm{N}$ (from [12]).

null ozone concentration between 14 and $20 \mathrm{~km}$ in altitude. The almost complete disappearance of ozone in the lower polar stratosphere is now a recurring feature of the southern Antarctic spring. In the Arctic, as suggested by the total column ozone measurements, the observations of the vertical profile in spring do not show a decrease of amplitude similar to that observed in Antarctica. Moreover, the ozone destruction is extremely variable from one year to another. The maximum decreases recorded in March 1996 and 2000, for example, reach more than 50\% compared to the 1970s climatological values, but it remains confined in a range of altitudes smaller than Antarctica, around $20 \mathrm{~km}$ altitude.

\subsection{Chemical processes}

The large spring ozone depletion observed in polar regions cannot be accounted for only by the catalytic cycles of destruction discussed previously. Indeed, most of them involve atomic oxygen $\mathrm{O}$ which is present in very small amounts in the altitude range of the polar ozone disappearance. The main catalytic cycle which is most significant in the lower stratosphere is the cycle 2 involving HOx radicals. It is not a viable option here because its efficiency is vastly insufficient to achieve a complete destruction of ozone during a month. When the ozone hole was discovered by a team from the British Antarctic Survey in 1985 [7], a rise of in atmospheric chlorine loading role of chlorine was proposed to try to explain a phenomenon that, at that time, was totally unexpected. As a result of human activities, the atmospheric concentration of chlorine has indeed grown almost exponentially since the mid-twentieth century, resulting in 6 -fold increase (more than $3 \mathrm{ppbv}$ nowadays) compared to pre-industrial values. By itself, this rapid change in the composition of the atmosphere does not seem able to explain the magnitude of the reduction of ozone observed over Antarctica. In addition to the absence of atomic oxygen $\mathrm{O}$ in the considered altitude range, it should be noted that the destruction of ozone occurs at latitudes and a season where the sun 


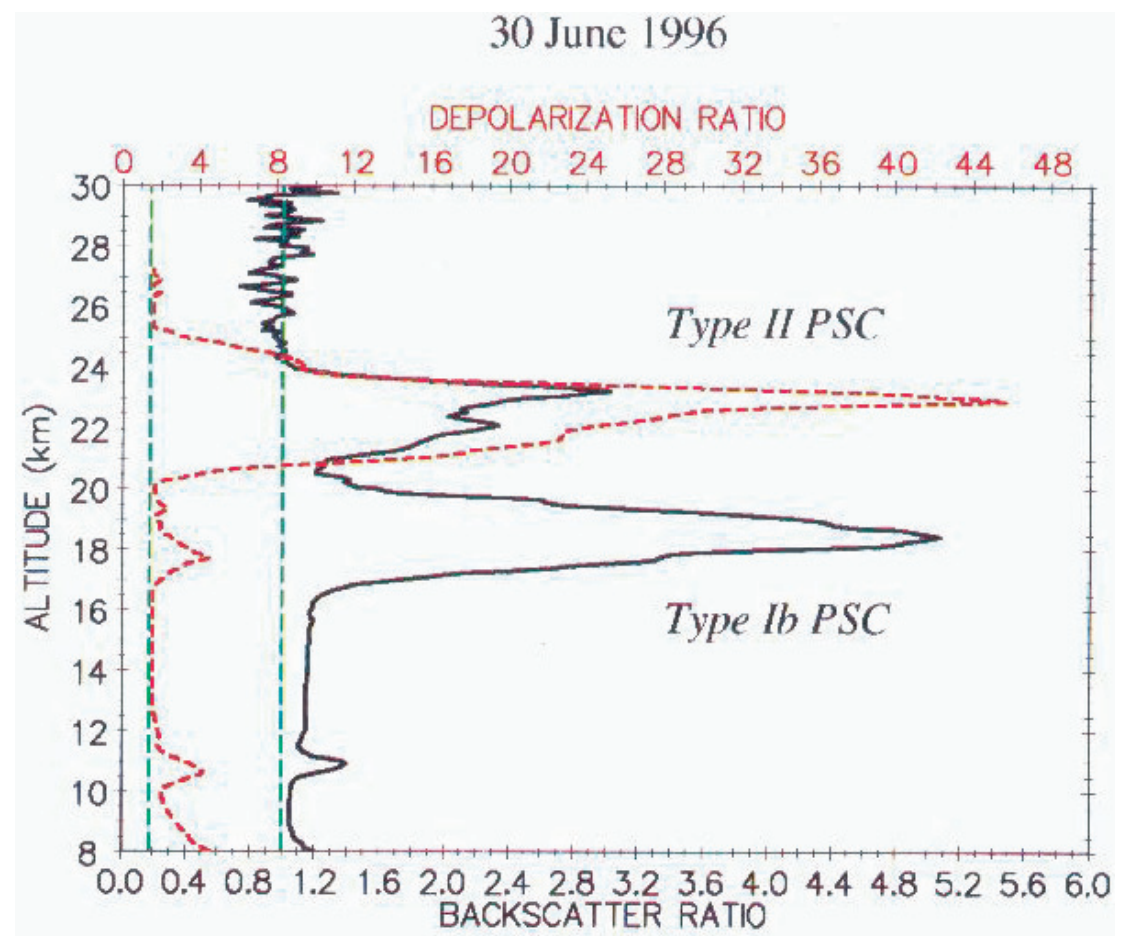

Fig. 8. Examples of vertical profiles of backscatter (solid line) and depolarization (dotted line) measured by lidar on 20 June 1996 over the Antarctic station of Dumont d'Urville. Such measurements reveal the presence of two layers of stratospheric clouds at 18 and $23 \mathrm{~km}$ in altitude. The lower layer is mainly composed of liquid droplets (low depolarization) while the top layer is composed of solid particles (strong depolarization).

low on the horizon limit the effectiveness of usual chlorine-catalysed cycles that are active at midlatitudes. The extensive program of experimental and theoretical research undertaken during the years 1980-1990, however, has helped to successfully identify the mechanisms responsible for the decrease of ozone over the polar regions. In particular, the responsibility of the increase in chlorine content of industrial origin is now established without ambiguity. As proposed by Solomon et al. [9] and McElroy et al. [10] in 1986, the destruction of polar ozone by chlorine compounds in the spring is due to the existence of heterogeneous chemical processes in these regions, occurring on the surface of polar stratospheric clouds.

\subsection{Polar stratospheric clouds}

After the autumn equinox, the polar regions are gradually deprived of sunlight and so do benefit anymore from heating associated with the absorption of ultraviolet radiation by ozone. The infrared cooling quickly generates very low temperatures in the stratosphere. Temperatures can reach $190 \mathrm{~K}$ in the Arctic and even down to $180 \mathrm{~K}$ in Antarctica. Although the stratosphere is very « dry »in terms of water vapour content (from about $5 \mathrm{ppm}$ ), the temperatures are low enough to allow the formation of clouds between 15 and $25 \mathrm{~km}$ (Fig. 8). Several types of polar stratospheric clouds (PSCs) have been identified. They are distinguished according to their optical properties, which depend on the size, state and composition. The crucial parameter in the processes of 
formation, evaporation and sublimation of PSCs is the temperature : its evolution usually determines changes in PSC composition and phase. The polar stratospheric clouds begin to form around $196 \mathrm{~K}$ to $50 \mathrm{hPa}$. At this temperature, water vapour and nitric acid present in the gas phase condense on liquid sulphuric acid aerosols present in the lower stratosphere and freeze to form solid crystals of nitric acid trihydrate (NAT: $\mathrm{HNO}_{3}-3 \mathrm{H}_{2} \mathrm{O}$ ). But, often, the particles do not freeze. In this case, at around $192 \mathrm{~K}$ they form liquid PSCs composed of ternary liquid solution $\mathrm{HNO}_{3}-\mathrm{H}_{2} \mathrm{O}-\mathrm{H}_{2} \mathrm{SO}_{4}$. PSCs have quite variable dimensions, but their typical size is several microns. When the temperature carries on dropping and reaches about $189 \mathrm{~K}$ (point of solid condensation of water vapor for a pressure of $50 \mathrm{hPa}$ ), most of the stratospheric water vapour condenses and freezes on pre-existing nitric acid-rich PSCs to form almost pure ice crystals. The ice particles are formed usually larger than those of NAT or ternary liquid particles, with a radius of about ten micrometers.

\subsection{Heterogeneous chemistry}

Polar stratospheric clouds provide reactive surfaces for chemical reactions that do not occur or are very slow in the gas phase. These reactions are called heterogeneous because they result from interactions between species in the gas phase and surfaces/volumes of solid or liquid phases. Although the exact mechanisms of some of these heterogeneous chemical reactions are not yet fully understood, many reactions have been identified in the laboratory. Among the most important heterogeneous reactions for polar stratospheric chemistry, one can cite the following two reactions:

$$
\begin{aligned}
& \mathrm{ClONO}_{2}+\mathrm{H}_{2} \mathrm{O} \stackrel{\text { het }}{\longrightarrow} \mathrm{HNO}_{3}+\mathrm{HOCl} \\
& \mathrm{ClONO} \mathrm{NO}_{2}+\mathrm{HCl} \stackrel{\text { het }}{\longrightarrow} \mathrm{HNO}_{3}+\mathrm{Cl}_{2} .
\end{aligned}
$$

These reactions very quickly convert the chlorine reservoir specis $\mathrm{HCl}$ and $\mathrm{ClONO}_{2}$ into much more unstable chlorine species $\mathrm{HOCl}$ and $\mathrm{Cl}_{2}$. These last species are indeed quickly photolysed at the end of winter when the sun comes back over the polar vortex to produced ozone-destroying radicals $\mathrm{Cl}$ and $\mathrm{ClO}$.

\subsection{Catalytic destruction of polar ozone}

The chlorine cycles of global ozone destruction are ineffective in the lower stratosphere due to the lack of atomic oxygen. In the polar vortex in winter, high concentrations of ClO generated by heterogeneous chemistry on polar stratospheric clouds greatly increase the probability that $\mathrm{ClO}$ react with itself to form a complex, the dimer $\mathrm{Cl}_{2} \mathrm{O}_{2}$ [11]. This three body reaction initiates a powerful ozone-destroying catalytic cycle in the winter polar regions, that is responsible for 50 to $70 \%$ of the observed ozone destruction:

Cycle 6

$$
\begin{gathered}
\mathrm{ClO}+\mathrm{ClO}+\mathrm{M} \stackrel{k_{\mathrm{ClO}+\mathrm{ClO}}}{\longrightarrow} \mathrm{Cl}_{2} \mathrm{O}_{2}+\mathrm{M} \\
\mathrm{Cl}_{2} \mathrm{O}_{2}+h \nu \stackrel{\mathrm{Jl}_{2} \mathrm{O}_{2}}{\longrightarrow} \mathrm{Cl}+\mathrm{ClO}_{2} \\
\mathrm{ClO}_{2}+\mathrm{M} \longrightarrow \mathrm{Cl}+\mathrm{O}_{2} \\
2\left(\mathrm{Cl}+\mathrm{O}_{3} \longrightarrow \mathrm{ClO}+\mathrm{O}_{2}\right) \\
\text { net: } \quad 2 \mathrm{O}_{3} \longrightarrow 3 \mathrm{O}_{2}
\end{gathered}
$$


This cycle does not need atomic oxygen and can therefore operate in the lower stratosphere. Moreover, it only needs little sunlight to operate effectively because of the photolysis of $\mathrm{Cl}_{2} \mathrm{O}_{2}$ is fast. It is the rate-limiting step in cycle 6 and so it determines the ozone destruction rate of the cycle. The chlorine dimer may also be thermally decomposed. However, at the low temperatures encountered in the polar vortex, the rate of thermal decomposition of $\mathrm{Cl}_{2} \mathrm{O}_{2}$ can usually be neglected against its photolysis. Assuming quasi-steady state for the dimmer (production = destruction), the rate of ozone destruction by cycle 6 can be written:

$$
\frac{d\left[\mathrm{O}_{3}\right]}{d t}=-2 \mathrm{~J}_{\mathrm{Cl}_{2} \mathrm{O}_{2}}\left[\mathrm{Cl}_{2} \mathrm{O}_{2}\right]=-2 k_{\mathrm{ClO}+\mathrm{ClO}}[\mathrm{ClO}][\mathrm{ClO}][\mathrm{M}]
$$

where the factor 2 is explained by the number of ozone molecules destroyed by number of molecules $\mathrm{Cl}_{2} \mathrm{O}_{2}$ photolysed. This expression shows that the rate of ozone destruction is proportional to the square of the concentration of chlorine. It is estimated that the levels of chlorine in the stratosphere have tripled since the 1960s, resulting in an increase by a factor 9 of ozone destruction rate by cycle 6 , the $\mathrm{ClO}$ dimer cycle. This quadratic dependence largely explains the relatively sudden appearance of the phenomenon of ozone hole. Due to the large increase in $\mathrm{ClO}$ concentrations, cycle 5 which couples $\mathrm{ClO}$ and $\mathrm{BrO}[10]$ becomes important in the polar regions during winter. This cycle is responsible for 30 to $50 \%$ of the total seasonal polar ozone loss. Along with the increase in atmospheric chlorine content, its role has also risen rapidly in recent decades as a result of increasing emissions of long-lived bromine-carrying compounds into the atmosphere. The spring destruction of polar ozone by the cycles described above continues until the warming of the polar vortex results in the evaporation of PSCs. Without the presence of heterogeneous chemistry on PSCs, chlorine radical concentrations rapidly decline and are converted back into reservoirs species.

\subsection{Interhemispheric differences}

The physical-chemical processes responsible for the seasonal ozone decline are identical in both polar vortexes. The fact that the ozone destruction is much more intense over Antarctica than over the Arctic is mainly due to differences in weather between the two hemispheres. Indeed, temperatures in the Arctic lower stratosphere in winter are on average $10 \mathrm{~K}$ higher than those observed in the Antarctic lower stratosphere (Fig. 9). They are also much more variable, because the winter temperature variations from one year to another can exceed ten degrees, while austral winter temperatures in the Antarctic lower stratosphere show little variability. These temperature differences between the two hemispheres are largely related to differences in the distribution of continents. Antarctica is isolated in the middle of the oceans in the Southern Hemisphere, while the northern hemisphere is characterized by alternating land and oceans, and a succession of zones of low and high pressures. The complex terrain and the contrasts in temperature of the Northern Hemisphere promote wave activity, which is a major source of disruption of the polar vortex. As a result, the Arctic vortex is generally less stable, warmer and less isolated from the mid-latitude than the Antarctic vortex. The formation of polar stratospheric clouds, necessary for the activation of chlorine, is more sporadic and less extensive in the Northern polar regions than in the Southern polar regions. Another important difference between the two hemispheres is the lifespan of the vortex, which is clearly linked to the stability and the warming of the polar stratosphere at the end of winter. The polar vortex is more disturbed in the Northern hemisphere than in the Southern hemisphere; it tends to heat up and to break up towards the end of winter in the Arctic before the light is completely back on the pole. The break up of the vortex causes a rapid deactivation of chlorine and hence the ozone depletion stops relatively early in the season. More stable, the Antarctic vortex in general lasts until the end of the austral spring, allowing cycles of ozone destruction to operate for a period of 2 to 3 months longer than in the Arctic. 


\section{Minimum Air Temperatures in the Polar Lower Stratosphere}

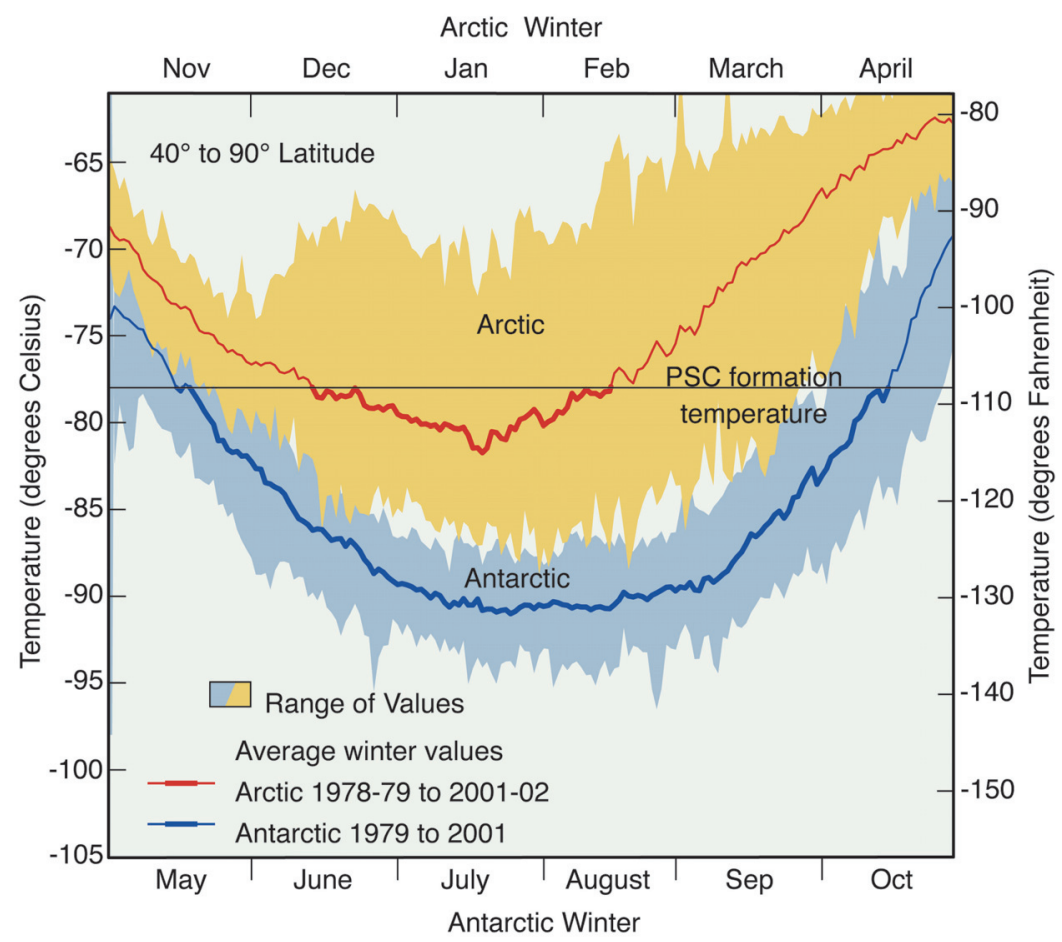

Fig. 9. Minimum temperatures at $50 \mathrm{hPa}$ observed in the Arctic and Antarctic over the period 19782001. The horizontal line at $195^{\circ} \mathrm{K}\left(\right.$ about $-78^{\circ} \mathrm{C}$ ) indicates the level of formation of polar stratospheric clouds (from [8]).

\section{Conclusions}

\subsection{Budget of stratospheric ozone}

The chemical balance equation of a species is usually written taking into account all reactions in which the considered species is a reactant or product. Regarding stratospheric ozone, it is possible to simplify the problem by considering the equation of the odd oxygen family $\mathrm{Ox}$, already discussed in the case of an atmosphere of pure oxygen. Considering only the important catalytic cycles of ozone destruction described previously, the evolution equation of odd oxygen in the stratosphere can be expressed by:

$$
\begin{aligned}
& \frac{d\left[O_{x}\right]}{d t}=2 J_{O_{2}}\left[O_{2}\right] \\
& -2 k_{O+O_{3}}[O]\left[O_{3}\right]-k_{O H+O_{3}}[O H]\left[O_{3}\right] \\
& -k_{\mathrm{HO}_{2}+\mathrm{O}}\left[\mathrm{HO}_{2}\right][\mathrm{O}]-k_{\mathrm{HO}_{2}+\mathrm{O}_{3}}\left[\mathrm{HO}_{2}\right]\left[\mathrm{O}_{3}\right] \\
& -2 k_{\mathrm{NO}_{2}+\mathrm{O}}\left[\mathrm{NO}_{2}\right][\mathrm{O}]-2 k_{\mathrm{ClO}+\mathrm{O}}[\mathrm{ClO}][\mathrm{O}] \\
& -2 k_{\mathrm{BrO}+\mathrm{ClO}}[\mathrm{BrO}][\mathrm{ClO}]-2 k_{\mathrm{ClO}+\mathrm{ClO}}[\mathrm{ClO}][\mathrm{ClO}][\mathrm{M}] \text {. }
\end{aligned}
$$

Recall that in the middle and lower stratosphere, we can consider that $\mathrm{Ox}=\mathrm{O}_{3}$ since the ozone concentration is far superior to that of atomic oxygen. In the upper stratosphere, we use the 
abundance ratio $\mathrm{O} / \mathrm{O}_{3}$ expressed in equation (3) to infer the evolution of ozone from that of Ox. For nitrogen, chlorine and bromine cycles, only the critical reactions appear in this budget, because the radicals produced by these reactions ( $\mathrm{NO}$ respectively, $\mathrm{Cl}$ and $\mathrm{Br}$ ) react very quickly and almost exclusively with $\mathrm{O}_{3}$ to reform the radical reactants $\left(\mathrm{NO}_{2}, \mathrm{ClO}\right.$ and $\left.\mathrm{BrO}\right)$. A factor of 2 is applied because two Ox molecules are destroyed each passage through these cycles. This approach can be applied to cycles of $\mathrm{OH}$ radicals hydrogenated or $\mathrm{HO}_{2}$. Indeed, they can also react with $\mathrm{O}_{3}$ well as atomic oxygen $\mathrm{O}$, with the predominance of a reaction over another that depends on the altitude and season considered. The reactions of $\mathrm{H}, \mathrm{OH}$ and $\mathrm{HO}_{2}$ with $\mathrm{O}$ and $\mathrm{O}_{3}$ are explicitly represented in the budget. However, the factor 2 is omitted to avoid double counting since all the reactions of the HOx cycles are included in the budget. For simplicity, the only ozone source term is the photolysis of molecular oxygen. Note that, in the very low stratosphere, the chain oxidation of methane can also lead to some ozone production.

The hydrogen radicals are responsible for most of the destruction of ozone in the lower stratosphere below $20 \mathrm{~km}$, while the cycle of nitrogen oxides dominate in the middle stratosphere. In the upper stratosphere, the contributions of each chemical family are almost equivalent to $40 \mathrm{~km}$. It is also at this altitude range that total rate of destruction of ozone equal its rate of production. Ozone can therefore be described as being in photochemical equilibrium. The ozone destruction rates vary with latitude and season and are very sensitive to the aerosol loading in the lower stratosphere.

\subsection{Past and future evolution of ozone at global scale}

The balance of stratospheric ozone is controlled by hydrogen, nitrogen, chlorine and bromine radicals (see Fig. 10), whose levels in the stratosphere are themselves determined by the levels of gas sources emitted at ground level. The main gas sources are water vapor and methane $\left(\mathrm{CH}_{4}\right)$ for hydrogen compounds, nitrous oxide $\left(\mathrm{N}_{2} \mathrm{O}\right)$ for nitrogen compounds, chlorofluorocarbons (CFCs) for chlorinated compounds, methyl bromide $\left(\mathrm{CH}_{3} \mathrm{Br}\right)$ and halons for brominated compounds. The most significant factor for the evolution of the ozone layer during the last century has been the considerable increase in industrial emissions of long-lived chlorine and bromine compounds. These gases are decomposed in the stratosphere under the influence of intense ultraviolet radiation, releasing the atoms of chlorine and bromine which are subsequently involved in the catalytic cycle of ozone destruction.

Because of the widespread use of chlorofluorocarbons in the industry, the stratospheric chlorine content has risen almost exponentially during the period 1970-1980 and is now three times higher than it was in the 1960s. As a result of growing emissions of halons, the stratospheric bromine content has also increased during the recent decades, although to a lesser extent the chlorine content. Indeed, the contribution of industrial activities to the bromine content is less important than to the stratospheric content: it only constitutes about half, against more than $80 \%$ for chlorine.

The measurements unambiguously show that the change in atmospheric composition since the 1980s has led to a reduction in stratospheric ozone globally (Fig. 11). The decline has reached today 3 to $4 \%$ in total column averaged over the year, a value far greater than the $1 \%$ natural variations of ozone. The minimum value at the global level was reached during the two years that followed the eruption of Pinatubo volcano in 1991 (-5\%). This major eruption had increased the aerosol loading in the stratosphere for several years, resulting in increased efficiency of heterogeneous chemical reactions and changes in atmospheric dynamics through perturbations of the Earth's radiation balance on a global scale.

The amplitude of long-term changes in the ozone layer varies with latitude and season (Fig. 11). The greatest reduction occurs at high latitudes in the southern hemisphere $(-10$ to $-20 \%$ annual average over the $60^{\circ}-70^{\circ} \mathrm{N}$ latitude range) as a result of Antarctic og ozone hole fg that forms each austral spring. In the northern hemisphere, the decrease is also maximum at high latitudes $\left(-5 \%\right.$ to $-6 \%$ annual average over the $60^{\circ}-70^{\circ} \mathrm{N}$ latitude range) caused also by 


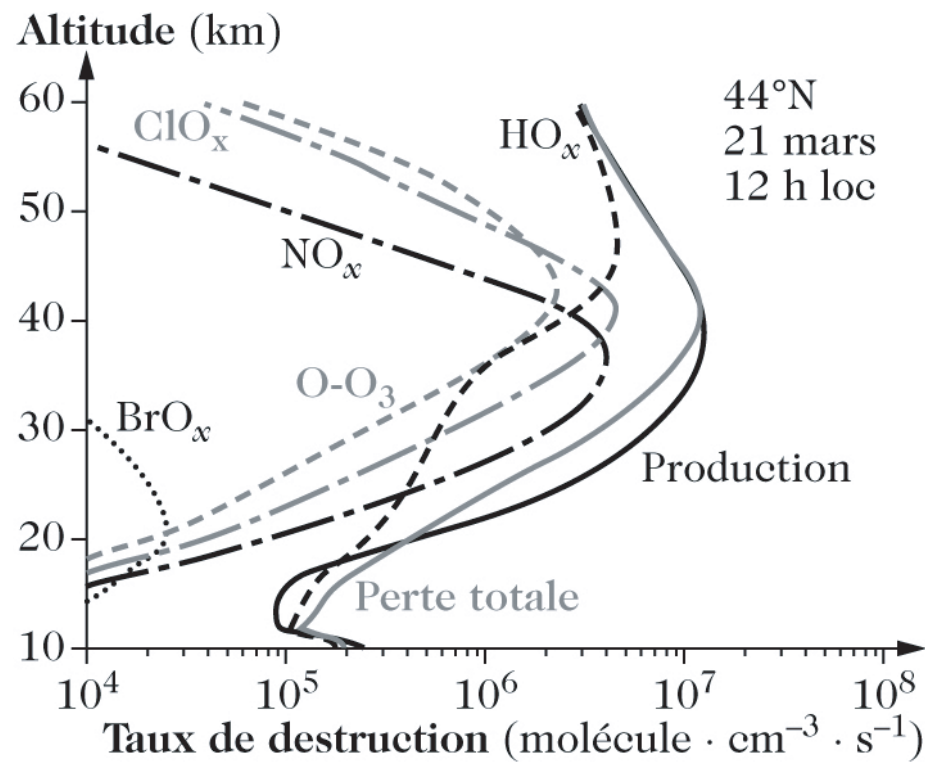

Fig. 10. Production rates and destruction of ozone by different chemical families at $44^{\circ} \mathrm{N}$ in March. The rates are calculated from the chemistry-transport model Reprobus for a background aerosol loading. The model simulations take into account the cycles represented in equation (8) and other ozone-destroying cycles such as the $\mathrm{ClO}+\mathrm{HO}_{2}$ cycle and the $\mathrm{BrO}+\mathrm{HO}_{2}$ cycle. For cycles catalysed by two different families of radicals, the contribution of the cycle is arbitrarily assigned to one of the family. The $\mathrm{ClO}+$ $\mathrm{HO}_{2}$ cycle is assigned to the chlorine family $\mathrm{ClOx}$; the $\mathrm{BrO}+\mathrm{ClO}$ and $\mathrm{BrO}+\mathrm{HO}_{2}$ cycles are attributed to the bromine family $\mathrm{BrOx}$ (from [12]).

ozone depletion inside the polar vortex during winter and spring. The decrease of ozone observed at mid-latitudes largely results from transport of ozone-depleted air from polar regions, as well as direct destruction of ozone by global catalytic cycles that do not require heterogeneous chemistry on stratospheric clouds, Finally, ozone does not change significantly in tropical regions.

Concerns arising from the discovery of the Antarctic ozone hole in 1985 and from a possible alteration of the stratospheric ozone layer by human activities have led to a process of regulating the production of long-lived compounds that are sources of chlorine and bromine in the stratosphere. The Montreal Protocol (1987) was negotiated and ratified by producing countries to conduct a concerted reduction in emissions which would ultimately lead to elimination of these products in the industry. The Protocol has been amended several times since 1987 by adopting increasingly stringent measures, or extending its scope to a larger number of chlorine and bromine-carrying gases. Developed countries have halted production of halons in 1994 and the most dangerous chlorinated products $\left(\mathrm{CFCs}\right.$, methyl chloroform $\mathrm{CH}_{3} \mathrm{CCl}_{3}$ and carbon tetrachloride $\mathrm{CCl}_{4}$ ) in 1996. A delay of 10 to 15 years has been granted to developing countries to enable them to adapt to substitute products. In most applications, CFCs are now replaced by hydrochlorofluorocarbons (HCFCs) that have much shorter lifetimes in the lower atmosphere or hydrofluorocarbons (HFCs) that contain no more halogen atoms.

Implementation of the Montreal Protocol has led to a stabilization of total chlorine content since mid-1990s. This is due mainly to the sharp decline in the atmospheric concentration of $\mathrm{CH}_{3} \mathrm{CCl}_{3}$ from 1990, whose lifetime of 5 years has allowed its relatively rapid elimination of the atmosphere once its production was interrupted. The main CFCs, CFC-11 and CFC-12, have lifetimes of several decades and so are eliminated from the atmosphere on the same time scales. The effectiveness of the Montreal Protocol is now well established with the atmospheric burden of CFC-11 (lifetime of about 45 years) declining since 1996, while that the burden of CFC-12 

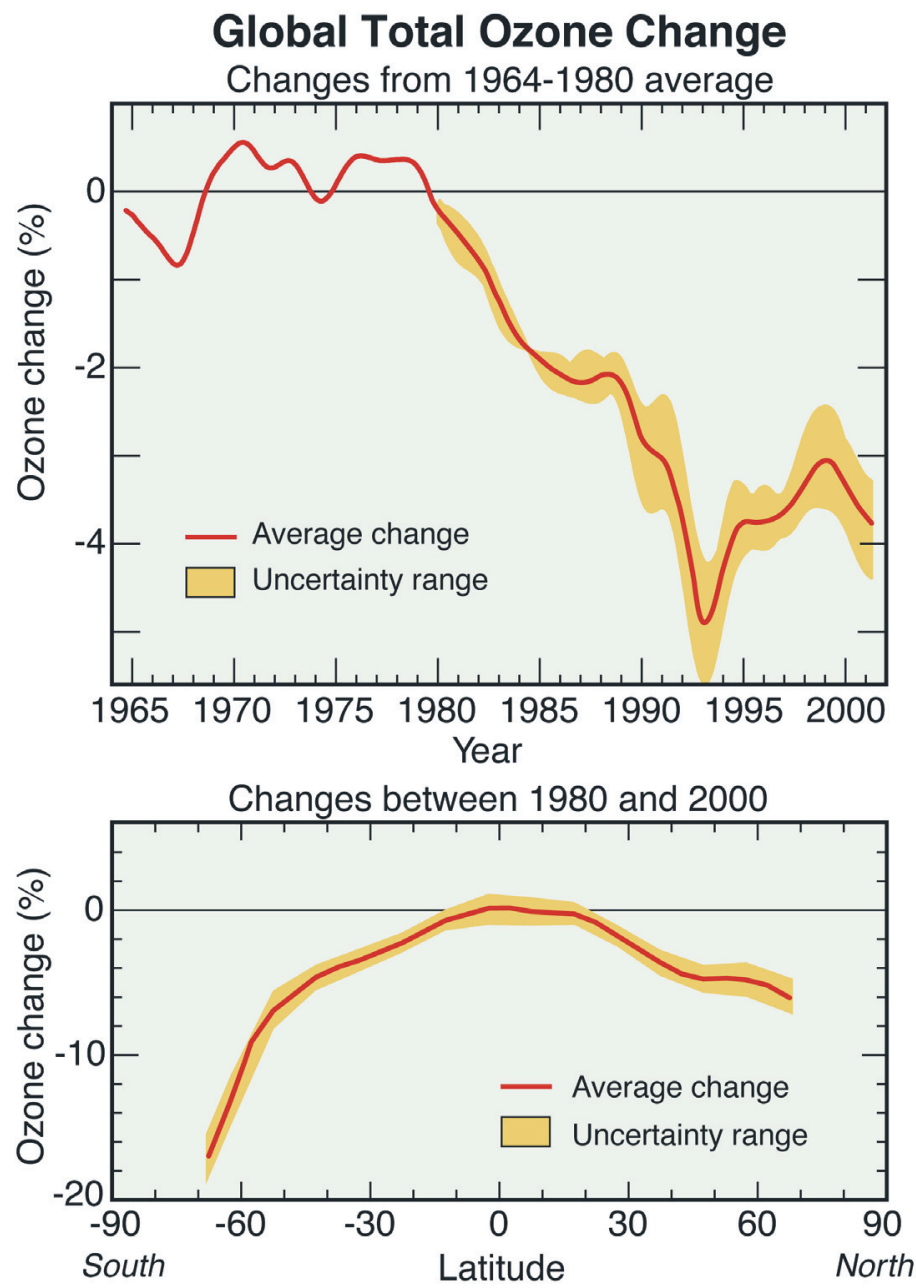

Fig. 11. Evolution of the globally averaged total ozone column (in \%) compared to the average over the period 1964-1980. (b) Evolution of the total ozone column (in \%) between 1980 and 2000 as a function of latitude (from [8]).

(lifetime of 100 years) has stabilized in 2000. Given these findings and the most probable scenarios of production, the most likely return to atmospheric chlorine contents comparable to those that preceded the appearance of the ozone hole is expected around the middle of this century (Fig. 13). A chlorine content equivalent to that of the 1950s (i.e. before the widespread use of CFCs) will probably not be reached before the end of this century.

The slow decay of stratospheric chlorine levels should lead to a gradual reduction of the large ozone losses in polar regions, and an overall increase in the thickness of the ozone layer. Today, most modelling works predict that the overall increase in stratospheric ozone should be detectable from 2010 while the return to the ozone levels of 1980, before the appearance of the ozone hole, is expected around 2050 (Fig. 13). It is worth pointing out that, although the chlorine content is the same, the atmospheric composition in 2050 will nevertheless be different from that of 1980 . Indeed, human activities since 1980 have led to an important increase in the concentrations of greenhouse gases such as $\mathrm{CO}_{2}, \mathrm{CH}_{4}$ and $\mathrm{N}_{2} \mathrm{O}$ which will carry on during this century. Although the magnitude of this future increase is now difficult to quantify, it is already well established 


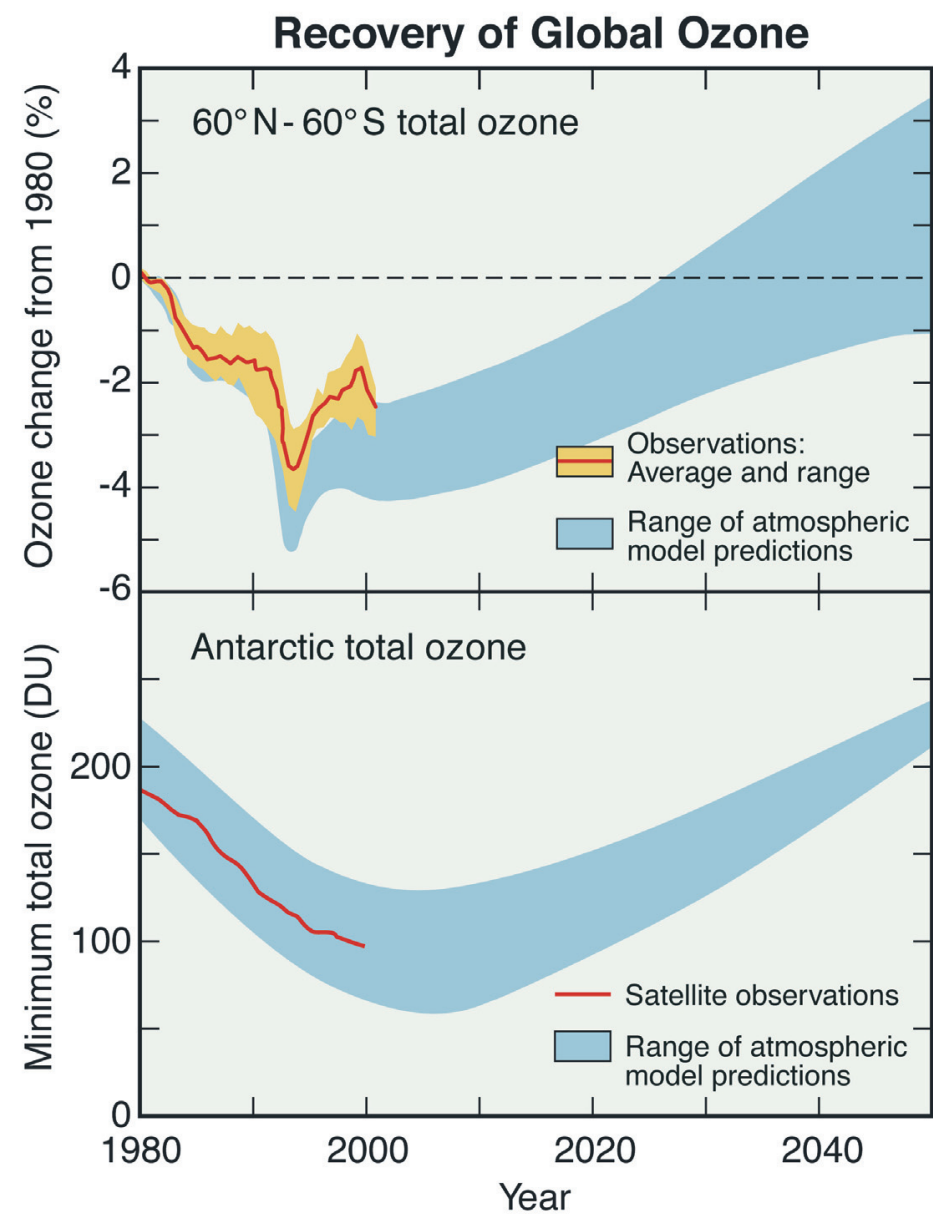

Fig. 12. Evolution of the total ozone column averaged over the $60^{\circ} \mathrm{S}-60^{\circ} \mathrm{N}$ latitude range (solid curve), and the range (shaded area) predicted by different models taking into account the evolution in chlorine and bromine gases and greenhouse gases over the 1980-2050 period. (b) Same as (a) but for the minimum ozone column above the Antarctic (after [8]).

that the growing emissions of greenhouse gases should lead to a warming of the Earth's surface and the lower atmosphere, accompanied by a cooling of the stratosphere. In the upper stratosphere, this cooling should result in increase in ozone because the efficiency of the catalytic ozone destruction decreases when the temperature decreases. In the lower stratosphere, on the contrary, lower temperatures will promote more frequent formation of stratospheric clouds and therefore will tend to counteract the effects of the chlorine reduction on the destruction of polar ozone in winter and spring. Our ability to predict the long-term evolution of temperature in the stratosphere has therefore become a key factor in determining the future of the ozone layer. In a sense, the issue of stratospheric ozone will be increasingly linked in the coming years with the issue of greenhouse gases emissions and climate change associated with it.

\section{References}

1. S. Chapman, Memoirs Royal Meteorolog. Soc. 3, 103 (1930)

2. D.R. Bates, M. Nicolet, J. Geophys. Res. 55, 301 (1950) 
3. P.J. Crutzen, Quart. J. Royal Meteorolog. Soc. 96, 320 (1970)

4. H.S. Johnston, Science 173, 517 (1971)

5. M.J. Molina, F.S. Rowland, Nature 249, 810 (1974)

6. S.C. Wofsy, M.B. McElroy, Y.L. Yung, Geophys. Res. Lett. 2, 215 (1975)

7. J.C. Farman, B.G. Gardiner, J.D. Shanklin, Nature 315, 207 (1985)

8. WMO (World Meteorological Organization), Scientific Assessment of Ozone Depletion: 2002, Geneva (2003), p. 498

9. S. Solomon, R. Garcia, F.S. Rowland, D.J. Wuebbles, Nature 321, 755 (1986)

10. M.B. McElroy, R.J. Salawitch, S.C. Wofsy, J.A. Logan, Nature 321, 759 (1986)

11. L.T. Molina, M.J. Molina, J. Phys. Chem. 91, 433 (1987)

12. F. Lefevre, S. Bekki, Chapter 6, Le système chimique stratospherique, in Environnement atmospherique: notions et applications, edited by R. Delmas, V.-H. Peuch, et G. Mâgie (Éditions Belin, Paris, 2006) 